\title{
Expectations and Contagion in Self-Fulfilling Currency Attacks
}

\author{
Todd Keister \\ Research and Statistics Group \\ Federal Reserve Bank of New York \\ Todd.Keister@ny.frb.org
}

February 14, 2006

\begin{abstract}
This paper shows how expectations-driven contagion of currency crises can arise even if the currency market has a unique equilibrium when viewed in isolation. The model of Morris and Shin (1998) is extended to allow speculators to trade in a second currency market. If speculators believe that a devaluation of this other currency will make a domestic devaluation more likely, they will engage in trades that link the two markets. A sharp devaluation of the other currency will then be propagated to the domestic market and will increase the likelihood of a crisis there, fulfilling the original expectations. Even though this contagion is driven solely by expectations, the model places restrictions on observable variables, and these restrictions are broadly consistent with existing empirical evidence.
\end{abstract}

I thank Huberto Ennis, Paula Hernandez-Verme, Max Stinchcombe, and seminar participants at Cornell, Texas A\&M, the University of Pennsylvania, Queen Mary University of London, the University of Alberta, the Federal Reserve Bank of Richmond, the 4th Annual University of Texas - ITAM Conference, and the World Congress of the Econometric Society for useful comments. The views expressed herein are those of the author and do not necessarily reflect those of the Federal Reserve Bank of New York or the Federal Reserve System. 


\section{Introduction}

One of the most striking features of the currency crises of the 1990s was their contagiousness: a sharp devaluation of one currency was often followed by devaluations of other, sometimes seemingly unrelated, currencies. The theoretical explanations for such contagion have fallen into two broad categories. One emphasizes links between the economic fundamentals of the countries involved. These links can either be real in nature, based on trade between the countries or competition in trade, or financial, in the form of investors or speculators holding substantial positions in each of the countries. A crisis in one currency market, in this view, can change the economic fundamentals in the market for another currency in such a way that a crisis there becomes more likely or perhaps inevitable. ${ }^{1}$ The second category of explanations emphasizes the self-fulfilling nature of currency crises: it is profitable for a speculator to attack a fixed exchange rate regime if and only if sufficiently many other speculators attack to cause a devaluation. In this view, a currency market can be viewed as a coordination game played by a large number of speculators. Such a game often has multiple equilibria, one where all speculators attack and a devaluation occurs and another where no one attacks and no devaluation occurs. Which equilibrium obtains depends entirely on the expectations of the speculators playing the game. This approach leads naturally to a simple theory of expectations-based contagion in which a devaluation in one currency market acts as a signal that coordinates agents' expectations on the crisis equilibrium in another market. ${ }^{2}$ Determining the underlying cause of the observed spread of currency crises across markets is important because the proper design of policies and institutions to limit contagion, and even the desirability of limiting contagion, depends critically on whether it is generated by fundamental links or by market expectations.

Recent work, beginning with Morris and Shin (1998), casts doubt on the multiple-equilibrium explanation by showing that the removal of the assumption that economic fundamentals are common knowledge can generate a unique equilibrium in an otherwise-standard currency crisis model. This result would seem to rule out expectations-driven contagion, since the economic fundamen-

$1 \quad$ See, for example, Gerlach and Smets (1995), Eichengreen, et al. (1996), Dornbusch et al. (2000), and Pritsker (2000).

2 See Obstfeld (1996), Krugman (1999), and Masson (1999). 
tals in each currency market must uniquely determine whether or not a crisis occurs there. Furthermore, the empirical evidence, while far from conclusive, seems to indicate that fundamental links between countries are an important source of contagion and hence also seems to point against the idea that expectations play a critical role. ${ }^{3}$ The goal of the present paper is to demonstrate that these results, both theoretical and empirical, are completely consistent with contagion being driven solely by agents' expectations. Even when a currency market has a unique equilibrium, expectations-driven contagion can occur across markets, and this contagion will appear to be driven by financial linkages between the markets.

The definition of contagion I adopt is following: contagion occurs when a devaluation of one currency increases the equilibrium probability that a second currency will be devalued. The key observation in this paper is that when speculators expect the occurrence of a crisis to be correlated across countries, they have an incentive to engage in financial market trades that create links between otherwise-separate currency markets. These links can then cause a crisis to spread across the markets in a way that fulfills the original expectations. The implications of this observation are derived below using a modified version of the model of Morris and Shin (1998). The value of the domestic currency is pegged in real terms (or, say, to the U.S. dollar), and a large number of speculators each decide whether or not to attack the currency. For illustration, I will refer to the domestic currency as the Brazilian real. ${ }^{4}$ The market for reales is exactly as in Morris and Shin (1998), and therefore this market, viewed in isolation, has a unique equilibrium. Whether or not a crisis occurs in this equilibrium depends on the domestic economic fundamentals, including the willingness of the domestic government to defend the peg and the ability of speculators to attack it.

Now suppose that, before this market takes place, another market meets where a foreign currency (which I will refer to as the ruble) is traded, also against the dollar. The market for rubles has the same structure as the one for reales described above, and the same speculators may choose to attack or not attack the ruble. However, the speculators may have less information about the state of economic fundamentals in the ruble market; their expertise, after all, is in speculating on the real. Each speculator's ability to attack the real is constrained by the level of wealth that she

3 See, for example, Glick and Rose (1999), Kaminsky and Reinhart (2000), and Van Rijckeghem and Weder (2001).

4 I should emphasize that this label is for illustration purposes only. No attempt is made here to explain any specific historical episode. 
brings to that market, which depends on the outcome of any trade she makes in the ruble market. Assume the economic fundamentals in the two markets are uncorrelated. Suppose a speculator nevertheless believes that there will be contagion. i.e., that a devaluation of the real becomes more likely following a devaluation of the ruble. Under this belief, her marginal utility of wealth entering the market for reales is higher if the ruble has been devalued than if it has not, since a devaluation of the ruble makes a (profitable) attack on the real more likely. The speculator would therefore like to transfer wealth from states of nature where the ruble is not devalued to states where it is. In other words, she has a natural incentive to sell the ruble short. This can be true even if the expected return to speculating on the ruble is negative, because this speculation yields a positive payoff in states of the world where her marginal utility of wealth is high, and the negative payoff comes in states where her marginal utility of wealth is low. If all other speculators in the market for reales share the belief that contagion will occur, they will all face this same incentive and hence will bet against the ruble. If a devaluation of the ruble does occur, then, the total wealth that speculators bring to the market for reales will rise. This increase in wealth enables the speculators to take larger positions against the real, which in turn makes a devaluation of the real more likely to occur in equilibrium. Hence the original expectations are fulfilled, and there is an equilibrium of the two-market model where contagion of a currency crisis occurs solely because agents believed it would occur.

When the expected return to speculating on the ruble is negative, the model has another equilibrium in which contagion does not occur. If speculators believe that a devaluation of the ruble will have no effect on the market for reales, they will have no incentive to trade in rubles and no financial links between the two markets will arise. The outcome of the market for reales will then be independent of whether or not a devaluation of the ruble occurs. Hence the model presented here can have multiple equilibria, but it should be emphasized that this model is fundamentally different from the multiple-equilibrium-based explanations of contagion offered in the previous literature. In the standard explanation, the domestic currency market (viewed in isolation) has multiple equilibria, and events in the foreign currency market serve only to select one of these equilibria. Such models do not explain why the event "devaluation of the ruble" should be the signal for agents to attack the real instead of the event "no devaluation of the ruble." In other words, these models can explain any correlation of outcomes across markets, positive or negative. The model presented 
here, in contrast, offers a genuine explanation of the contagion of crises: a sharp devaluation of the ruble can lead to a significant change in the wealth of speculators on the real, while a lack of devaluation cannot.

The model places other restrictions on the structure of equilibrium contagion as well. The probability of a crisis in the market for reales, for example, is strictly increasing in the size of the devaluation of the ruble. The model therefore predicts that contagion should be most frequently observed following large devaluations. In addition, the model predicts that a currency crisis is more likely to occur when domestic fundamentals are weak than when they are strong. These restrictions derive from the fact that, at one level, the mechanism for contagion studied here is fundamental; contagion results from financial linkages between the two currency markets. In this way, the present work is related to a number of papers that study how financial interdependence can lead to the contagion of crises. ${ }^{5}$ In the previous literature, however, the financial linkages arise for fundamental reasons. In Goldstein and Pauzner (2004), for example, investors choose to invest in multiple markets for diversification purposes, and this decision creates the links between markets that lead to contagion. The point of the present paper is that these links can also arise solely as a result of agents' expectation that contagion will occur. Empirical evidence of the importance of financial links as a source of contagion should therefore be interpreted with caution. In particular, such results do not demonstrate that expectations are unimportant or that contagion is an inevitable outcome. Rather, the observed links could be a manifestation of self-fulfilling beliefs in contagion.

The remainder of the paper is organized as follows. The next section presents a modified version of the model of Morris and Shin (1998) in which trading on a second currency market is possible. Section 3 analyzes equilibrium in this model under various assumptions about the accessibility of the second market to speculators and provides conditions under which equilibrium contagion arises. Section 4 contains a discussion of the results, including an analysis of the relationship between the model presented here and the classic sunspots model of Cass and Shell (1983).

\section{The model}

The model is presented in two steps. First I describe the model of the market for the domestic currency in isolation. This model is nearly identical to that in Morris and Shin (1998), and hence

\footnotetext{
5 See Allen and Gale (2000), Goldstein and Pauzner (2004), and Kodres and Pritsker (2002).
} 
the description given here is brief. I then add the possibility of speculation in the market for another currency, so that contagion across markets can be studied.

\subsection{The domestic currency market}

The domestic government has pegged the exchange rate at $e^{*}$ dollars per unit of local currency. The economy is characterized by a fundamental "strength" $\theta \in[0,1]$, which determines what the exchange rate would be in the absence of government intervention in the currency market. The variable $\theta$ captures the demand for the domestic currency for international trade, foreign direct investment, and other purposes. The exchange rate if the government takes no action will be given by $f(\theta)$, where $f$ is continuous and strictly increasing. It is assumed that $e^{*}=f(1)$ holds. In other words, at the pegged value of the exchange rate, the domestic currency is overvalued in almost all possible states of the economy. The government must decide whether to take the actions necessary to maintain the peg, or to abandon the peg and let the exchange rate fall to the market value $f(\theta)$.

There is a $[0,1]$ continuum of identical speculators, each of whom has the ability to "attack" the domestic currency by selling it short. Short sales are limited by the speculator's wealth, which is denominated in dollars. In particular, each unit of wealth allows a speculator to short-sell one unit of the domestic currency. ${ }^{6}$ Each speculator has $w$ units of wealth available. Morris and Shin (1998) set $w=1$ and provided an informal discussion of the comparative static results with respect to the level of wealth. Wealth enters the model here in a way that corresponds to their discussions. Speculators are risk neutral, and therefore their choice set is essentially binary: either a speculator will attack with all of her wealth or she will not attack at all. There is a cost $t$ that a speculator must pay for each unit of the currency she sells short; one can think of this cost as the interest rate differential between the domestic currency and dollars. If a speculator chooses to attack the currency, her net gain will be $w\left(e^{*}-f(\theta)-t\right)$ if the government abandons the peg and $(-w t)$ if the peg is maintained.

The government receives a value $v>0$ if the peg is maintained. It will choose to maintain the peg if and only if this benefit is greater than the cost of doing so. The cost of maintaining the peg depends on on two things: the state of the economy and the size of the attack against the currency. This cost is represented by the function $c(z, \theta)$, where $z$ is the size of the attack (i.e., the number

\footnotetext{
6 This one-for-one property is just a choice of units.
} 
of units of domestic currency sold short). The function $c$ is continuous, strictly increasing in $z$, and strictly decreasing in $\theta$. Furthermore, the two conditions

$$
c(0,0)>v \quad \text { and } \quad c(1,1)>v
$$

are assumed to hold. The first says that in the worst state of fundamentals, the peg will be abandoned even if there is no attack against the currency. The second says that even in the best state of fundamentals, the peg will be abandoned if the size of the attack is equal to the initial wealth of all speculators. See Morris and Shin (1998) for a discussion of the role of these conditions in the analysis.

The timing of events is as follows. Each speculator begins with a belief about $\theta$ that is represented by a uniform distribution on $[0,1]$. Nature then draws the true value of $\theta$ from this distribution. Speculators do not observe the true state. Rather, speculator $i$ observes a signal $x_{i}$ which is drawn from a uniform distribution over the interval $[\theta-\varepsilon, \theta+\varepsilon]$, where $\varepsilon$ is a small but positive number. A law of large numbers is assumed, so that the distribution of signals received by the different speculators is also uniform on $[\theta-\varepsilon, \theta+\varepsilon]$. Based on her signal, each speculator decides whether or not to attack the currency. Next, the government observes the true value of $\theta$ and the size of the attack $z=w \alpha$, where $\alpha$ is the fraction of speculators who chose to attack. The government then decides whether abandon or maintain the peg, and payoffs are realized.

The model presented so far is identical to that in Morris and Shin (1998) except that the wealth level of each speculator is treated parametrically rather than being fixed at unity. As such, for $w$ close enough to unity the results derived by Morris and Shin continue to hold. In particular, the game described above has a unique Bayesian Nash equilibrium for any $\varepsilon>0$. In this equilibrium, there exists a cutoff value $\theta^{*}$ such that the peg is abandoned if $\theta \leq \theta^{*}$ and is maintained if $\theta>\theta^{*}$. In the limit as $\varepsilon$ goes to zero, the cutoff value can be characterized in the following way. Define $a(\theta, w)$ to be the smallest fraction of speculators (each with wealth $w$ ) whose attack would lead the government to abandon the peg when $\theta$ is the true state of the economy. That is, the function $a(\theta, w)$ is implicitly defined by

$$
c(w \cdot a(\theta, w), \theta) \equiv v
$$

It is straightforward to show that $a$ is increasing in $\theta$ and decreasing in $w$. Define $g(\alpha, \theta, w)$ to be 
the net benefit of attacking when a fraction $\alpha$ of the other agents attack. Then we have

$$
g(\alpha, \theta, w)=\left\{\begin{array}{c}
w\left(e^{*}-f(\theta)-t\right) \\
-w t
\end{array}\right\} \quad \text { if } \quad\left\{\begin{array}{c}
\alpha \geq a(\theta, w) \\
\alpha<a(\theta, w)
\end{array}\right\}
$$

More recent work by Morris and Shin (2003) shows that the cutoff value $\theta^{*}$ must satisfy

$$
\int_{0}^{1} g\left(\alpha, \theta^{*}, w\right) d \alpha=0 .
$$

In other words, an agent whose belief about the actions of other agents can be represented by a uniform distribution for $\alpha$ on $[0,1]$ must be indifferent between attacking and not attacking at $\theta^{*}$. This condition can be viewed as a definition of risk dominance for symmetric binary-action games games with a continuum of players. ${ }^{7}$ The results of Morris and Shin can therefore be interpreted as saying that, in the limit as the noise on the individual signals goes to zero, the global games approach "selects” the risk-dominant equilibrium of the common-knowledge game.

Using expression (1), the equation above can be rewritten as

$$
[1-a(\theta, w)] w\left(e^{*}-f(\theta)-t\right)+a(\theta, w)(-w t)=0
$$

and therefore the equilibrium value of $\theta^{*}$ will solve

$$
\left(1-a\left(\theta^{*}, w\right)\right)\left(e^{*}-f\left(\theta^{*}\right)\right)=t
$$

This expression implicitly defines a function $\theta^{*}(w)$ with the following property: in the unique equilibrium of this model, a devaluation will occur if $\theta \leq \theta^{*}(w)$ holds and will not occur if $\theta>\theta^{*}(w)$ holds. In the analysis that follows, the properties of this function play a critical role. The proposition below, which was first shown by Heinemann (2000), states that when speculators have more wealth, the set of states in which a devaluation occurs becomes strictly larger. ${ }^{8}$

Proposition 1 The equilibrium cutoff value $\theta^{*}$ is strictly increasing in the wealth level of speculators $w$.

A simple proof of this result can be obtained by implicitly differentiating (2).

\footnotetext{
7 See Harsanyi and Selten (1988) for a detailed discussion of risk dominance in finite-player games.

8 In their informal discussion, Morris and Shin (1998) said that the cutoff $\theta^{*}$ is increasing in the wealth of speculators when $\varepsilon$ is large, but that this effect disappears as $\varepsilon$ goes to zero. Heinemann (2000) corrected their calculations and showed that the effect remains present in the limit.
} 
Continuing to focus on the limiting case as $\varepsilon$ goes to zero, consider the expected utility level of a speculator who enters this market with wealth $w_{i}$ (which in principle could be different from the wealth level $w$ of other speculators). If the realization of $\theta$ is less than $\theta^{*}(w)$, a devaluation occurs and the speculator will gain the amount $\left(e^{*}-f(\theta)-t\right)$ for each unit of wealth that she has available. Her final wealth level, and hence her consumption, will then be

$$
w_{i}\left(1+e^{*}-f(\theta)-t\right)
$$

If the realization of $\theta$ is higher than $\theta^{*}(w)$, the speculator takes no action and simply consumes her wealth. ${ }^{9}$ The speculator's marginal utility of wealth is therefore equal to

$$
1+\int_{0}^{\theta^{*}(w)}\left(e^{*}-f(\theta)-t\right) d \theta \equiv \mu(w) .
$$

It is important to keep in mind that this marginal utility is independent of her own wealth level $w_{i}$ because she is risk neutral. However, it does depend on the wealth level $w$ of the other speculators in the market because $w$ determines the set of states in which a devaluation occurs. In fact, using Proposition 1, it is easy to see that the function $\mu$ defined in (3) is strictly increasing in $w$. The more wealth the other speculators have, the higher is the marginal value of wealth for an individual speculator. In other words, in addition to the usual complementarity in actions (i.e., attacking is more attractive when other agents attack), this model also exhibits complementarity in wealth levels. This property is crucial to the analysis that follows and is worth repeating: in the MorrisShin model, the marginal utility of wealth of an individual speculator is strictly increasing in the wealth level of other speculators.

\subsection{Speculation on another currency}

I now introduce the possibility for agents in the model to speculate in another market, where a foreign currency is traded (also against the dollar). This market meets before the domestic currency market, and before speculators receive their signals about the strength of the domestic economy. The basic structure of this market is that same as that described above. The foreign government has pegged its exchange rate at $e_{F}^{*}$ dollars per unit of foreign currency and must decide whether to maintain this peg or abandon it. The fundamental state of the foreign economy is denoted $\theta_{F} \in$

9 When $\varepsilon$ is arbitrarily small, the speculator's signal about $\theta$ is very accurate and hence she is able to attack in precisely the set of states in which a devaluation occurs. 
$[0,1]$, and speculators' initial belief about this variable is represented by a uniform distribution on $[0,1]$. As above, the variable $\theta_{F}$ includes the effects of all influences on the value of the foreign currency other than the actions of the agents in this model. If the peg is abandoned, the value of the foreign currency will be given by $f\left(\theta_{F}\right)$, where $f$ is again continuous and strictly increasing with $e_{F}^{*}=f(1)$. The government receives a value $v_{F}$ from maintaining the peg, and will do so if this value is greater than the cost $c_{F}\left(\theta_{F}, z_{F}\right)$, where $z_{F}$ is the size of the speculative attack against the foreign currency. The variables $\theta$ and $\theta_{F}$ are uncorrelated; in other words, the economic fundamentals in the two countries are assumed to be completely unrelated.

The foreign currency market differs from the domestic market in one key respect: speculators may or may not receive a signal about the state of fundamentals $\theta_{F}$. The idea here is that a speculator in this model, as in Morris and Shin (1998), naturally operates in the domestic currency market and hence necessarily has good information about the fundamentals in that market. The fundamentals in the foreign currency market, however, are completely unrelated and may not naturally be part of her information set. Both cases are studied below, where I argue that the case where speculators are not well informed about $\theta_{F}$ is the more interesting one.

As in the domestic market, each speculator can choose to attack the foreign currency by selling it short, and short sales are restricted by a speculator's wealth. At the beginning of time, each speculator has one unit of wealth. Because she is risk neutral, she will either attack the foreign currency with all of this wealth or not at all. There is a cost $t_{F}$ for each unit of foreign currency sold short, so that the net gain of attacking per unit of wealth is $\left(e_{F}^{*}-f\left(\theta_{F}\right)-t_{F}\right)$ if the peg is abandoned and $\left(-t_{F}\right)$ if it is maintained.

The question of interest in this paper is under what conditions the outcome in the foreign currency market has an impact on the domestic market. I will say that contagion occurs if the occurrence and/or size of a devaluation of the foreign currency affects the equilibrium probability distribution over outcomes in the domestic market; this statement is equivalent to the following definition.

Definition: Contagion is said to occur if the equilibrium cutoff value $\theta^{*}$ in the domestic market depends on the realization of the foreign fundamentals $\theta_{F}$. 


\section{Equilibrium}

This section presents the analysis of equilibrium contagion in the model for three different cases, depending on the access speculators have to the foreign currency market. In the first case, it is simply assumed that speculators cannot trade on the foreign market; this case serves as a useful benchmark. In the second case, speculators can place trades in the foreign market and receive signals about foreign economic fundamentals exactly as in the domestic market. In the final (and most interesting) case, speculators are free to trade in the foreign market but do not receive signals about foreign economic fundamentals. In each case, the question of interest is whether or not contagion can occur in equilibrium and, if it can, what form it takes.

\subsection{Foreign speculation not allowed}

First suppose that speculators are not allowed to trade in the foreign currency market. Solving for the equilibrium of the model is then straightforward. Each speculator will enter the domestic currency market with her original wealth level of one, and hence the game played in this market will be exactly that of Morris and Shin (1998). There is a unique equilibrium in this market, and for the limiting case as $\varepsilon$ goes to zero the cutoff level $\theta^{*}(1)$ is implicitly defined in (2). In particular, this cutoff level is necessarily independent of events in the foreign currency market. There is no contagion: regardless of the realization of foreign fundamentals $\theta_{F}$, the unique equilibrium in the domestic currency market is characterized by the same cutoff level. This simple result will be a useful benchmark in what follows.

Proposition 2 If speculators cannot trade in the foreign currency market, there is a unique equilibrium and no contagion occurs.

This proposition shows that the simple type of expectations-driven contagion discussed in the Introduction cannot occur in this model. If there are no links between the two currency markets, the unique equilibrium in the domestic market must be played regardless of what happens in the foreign market. The outcome in the foreign market is also easy to determine, since the only active agent is the foreign government. A devaluation occurs in this market if and only if the fundamentals are so bad that the cost of defending the peg when no one attacks is larger than the value of doing 
so, that is, if

$$
c_{F}\left(\theta_{F}, 0\right) \leq v_{F}
$$

holds. Let $\underline{\theta}_{F}$ be the state at which the above expression holds with equality, so that a devaluation of the foreign currency occurs whenever $\theta_{F} \leq \underline{\theta}_{F}$ holds.

\subsection{Informed speculation}

For the sake of comparison, consider now the other extreme case, where speculators can freely trade in the foreign market and are as informed about foreign economic fundamentals as they are about domestic fundamentals. Notice that attacking the foreign currency is not a risky undertaking in this environment. In equilibrium, a speculator knows $\theta_{F}$ arbitrarily well and will therefore be able to attack in only those states where a devaluation will occur. The following proposition shows that, in this case, contagion must occur.

Proposition 3 When speculators are informed about $\theta_{F}$, contagion must occur in equilibrium.

Proof: An equilibrium without contagion would require, by Proposition 1, that speculators enter the domestic currency market with the same level of wealth for every realization of $\theta_{F}$. However, when speculators are informed about the state of foreign fundamentals, it is a dominant strategy to attack the foreign currency when $\theta_{F} \leq \underline{\theta}_{F}$ holds. A devaluation will always occur in these states, so any equilibrium must have

$$
w=1+e_{F}^{*}-f\left(\theta_{F}\right)-t_{F}>1
$$

for $\theta_{F} \leq \underline{\theta}_{F}$. Similarly, not attacking is a dominant strategy for values of $\theta_{F}$ close enough to one, because in such cases the gain from a devaluation if it occurs would be less than the cost $t_{F}$ of attacking. Thus any equilibrium must have $w=1$ for realizations of $\theta_{F}$ close enough to one. Contagion therefore occurs.

This result simply reflects the fact that when speculators are well informed about foreign economic fundamentals, they will necessarily be active in the foreign currency market in some states of the world. In a sense, this type of contagion is not surprising. The two currency markets are fundamentally linked, because the same set of speculators naturally operates in both of them. In 
such a case, contagion of crises across markets must occur. This result is therefore similar in spirit to those of Allen and Gale (2000) and Goldstein and Pauzner (2004). The more interesting question in the current setting is what forces might drive contagion across markets that are, at least in principle, unrelated. Addressing this question requires changing the model so that speculators are not naturally active in the foreign market. In the next subsection, this is done by assuming that speculators are less well informed about foreign economic fundamentals than about domestic fundamentals.

\subsection{Uninformed speculation}

Now suppose that speculators are allowed to trade in the foreign currency market, but that they do not receive any signals about the foreign economic fundamentals. Instead, the decision of whether or not to attack the foreign currency must be made based on the prior belief about $\theta_{F}$. In this case, attacking the foreign currency is no longer a riskless undertaking. A speculator who chooses to attack will gain in some states of the world and lose in others. In addition, suppose the parameter values are such that attacking is relatively unattractive. To begin with, assume

$$
\int_{0}^{\underline{\theta}_{F}}\left(e_{F}^{*}-f\left(\theta_{F}\right)\right) d \theta_{F}<t_{F}
$$

holds. This condition says that the expected value of attacking the foreign currency when no one else attacks (and one's belief about $\theta_{F}$ is uniform on $[0,1]$ ) is negative. Everything on the lefthand side of this inequality (including $\underline{\theta}_{F}$ ) is independent of $t_{F}$, and hence this condition simply requires that $t_{F}$ not be too small. If this inequality were reversed, risk neutral speculators would always want to gamble in the foreign currency market. In such a case, links between the two markets would arise simply because both offer attractive trading opportunities to the same set of speculators, and contagion between these markets would necessarily arise as in Proposition 3. Instead, condition (4) requires that, a priori, the foreign currency market represent an unattractive gamble to the speculators in the model.

Under this condition, the equilibrium discussed in Section 3.1 is also an equilibrium in the current setting. To see this, consider the problem of an individual speculator who believes that no other speculators will attack the foreign currency. If she were to attack, her expected wealth 
entering the domestic currency market would be

$$
1+\int_{0}^{\underline{\theta}_{F}}\left(e_{F}^{*}-f\left(\theta_{F}\right)\right) d \theta_{F}-t_{F}<1 .
$$

Her marginal utility of wealth in the domestic market will equal $\mu(1)$, as defined in (3), regardless of the realization of $\theta_{F}$. She would therefore choose not to attack. Hence there is an equilibrium where none of the speculators attack the foreign currency, and all enter the domestic currency market with a wealth level of one. The equilibrium cutoff in the domestic market given by $\theta^{*}(1)$, independent of the realization of $\theta_{F}$, and no contagion occurs. This discussion is summarized in the following proposition.

Proposition 4 When speculators are uninformed about $\theta_{F}$ and (4) holds, there is an equilibrium where no speculator attacks the foreign currency and no contagion occurs.

There may, however, be other equilibria. Define

$$
\underline{t}_{F} \equiv \int_{0}^{\underline{\theta}_{F}}\left(e_{F}^{*}-f\left(\theta_{F}\right)\right) d \theta_{F}
$$

so that condition (4) can be rewritten as $t_{F}>\underline{t}_{F}$. The next proposition shows that, for values of $t_{F}$ close enough to $\underline{t}_{F}$, there also exists an equilibrium in which contagion occurs.

Proposition 5 There exists $\bar{t}_{F}>\underline{t}_{F}$ such that for any $t_{F} \in\left(\underline{t}_{F}, \bar{t}_{F}\right)$, there is an equilibrium where all speculators attack the foreign currency and contagion occurs.

Proof: Suppose all speculators but one are attacking the foreign currency, and consider the decision problem of the remaining speculator. The total size of the attack against the foreign currency in this case will be $z_{F}=1$, so the foreign government will defend the peg if and only if

$$
c_{F}\left(\theta_{F}, 1\right)<v_{F}
$$

holds. Let $\widehat{\theta}_{F}$ denote the unique value of $\theta_{F}$ for which the above relationship holds with equality, so that a devaluation will occur for $\theta_{F} \leq \widehat{\theta}_{F}$ but not for $\theta_{F}>\widehat{\theta}_{F}$. Define $w\left(\theta_{F}\right)$ to be the wealth level of each speculator who attacks the foreign currency, measured after payoffs in the foreign 
market are realized. Then we have

$$
w\left(\theta_{F}\right)=\left\{\begin{array}{ccc}
1+e^{*}-f\left(\theta_{F}\right)-t_{F} & \text { if } & \theta_{F} \leq \widehat{\theta}_{F} \\
1-t_{F} & \theta_{F}>\widehat{\theta}_{F}
\end{array}\right\}
$$

If the speculator whose problem we are considering attacks the foreign currency, her wealth going into the domestic currency market will also be equal to $w\left(\theta_{F}\right)$. If she does not attack, her wealth level will be equal to one. Recalling that the marginal utility of wealth in the domestic market is given by $\mu(w)$ as defined in (3), her total expected utility if she attacks the foreign currency is

$$
\int_{0}^{1} \mu\left(w\left(\theta_{F}\right)\right) w\left(\theta_{F}\right) d \theta_{F}
$$

and her total expected utility if she does not attack is

$$
\int_{0}^{1} \mu\left(w\left(\theta_{F}\right)\right) d \theta_{F}
$$

The expected gain from attacking can therefore be written as

$$
\int_{0}^{\widehat{\theta}_{F}} \mu\left(w\left(\theta_{F}\right)\right)\left(e_{F}^{*}-f\left(\theta_{F}\right)-t_{F}\right) d \theta_{F}+\int_{\widehat{\theta}_{F}}^{1} \mu\left(w\left(\theta_{F}\right)\right)\left(-t_{F}\right) d \theta_{F} .
$$

Suppose we evaluate this expression at $\underline{t}_{F}$. Recall that $\underline{t}_{F}$ satisfies

$$
\int_{0}^{\underline{\theta}_{F}}\left(e_{F}^{*}-f\left(\theta_{F}\right)-\underline{t}_{F}\right) d \theta_{F}+\int_{\underline{\theta}_{F}}^{1}\left(-\underline{t}_{F}\right) d \theta_{F}=0 .
$$

Using the definitions

$$
c_{F}\left(\widehat{\theta}_{F}, 1\right)=v_{F} \quad \text { and } \quad c_{F}\left(\underline{\theta}_{F}, 0\right)=v_{F}
$$

we clearly have $\widehat{\theta}_{F}>\underline{\theta}_{F}$. Furthermore, we know from (5) that $w\left(\theta_{F}\right)>1$ holds for $\theta_{F} \leq \widehat{\theta}_{F}$ and $w\left(\theta_{F}\right)<1$ holds for $\theta_{F}>\widehat{\theta}_{F}$. Together, these relationships imply that the value of (6) evaluated at $t_{F}=\underline{t}_{F}$ is strictly positive. By continuity, it is therefore positive on an open interval of values around $\underline{t}_{F}$. Hence there exists a value $\bar{t}_{F}$ such that for any $t_{F} \in\left(\underline{t}_{F}, \bar{t}_{F}\right)$, there is an equilibrium in which all speculators attack the foreign currency.

All that remains to be shown is that contagion occurs in this equilibrium. This fact follows directly from (5) and Proposition 1. When all speculators are attacking the foreign currency, the wealth levels they carry into the domestic market depend in a non-trivial way on the realization of 
$\theta_{F}$. Since the equilibrium cutoff value $\theta^{*}$ is strictly increasing in this wealth level, contagion must occur.

The fact that other speculators are attacking the foreign currency makes attacking more attractive to an individual in two ways. First, the attack makes a devaluation of the foreign currency more likely, as reflected in the above calculations by the relationship $\widehat{\theta}_{F}>\underline{\theta}_{F}$. This effect represents the complementarity in actions that is standard in coordination games. The second, and more interesting, effect is that the attack by others will induce a correlation between the returns in the two markets, and this correlation will make attacking more attractive to an individual. We can isolate this second effect, which derives from the complementarity in wealth levels described above, by imposing a stronger condition than (4) on the cost $t_{F}$. Define

$$
\widehat{t}_{F} \equiv \int_{0}^{\widehat{\theta}_{F}}\left(e_{F}^{*}-f\left(\theta_{F}\right)\right) d \theta_{F}
$$

When $t_{F}>\widehat{t}_{F}$ holds, the expected return to attacking the foreign currency is negative even when all other speculators are attacking. Nevertheless, equilibrium contagion can still occur. To see this, rewrite (7) as

$$
\int_{0}^{\widehat{\theta}_{F}}\left(e_{F}^{*}-f\left(\theta_{F}\right)-\widehat{t}_{F}\right) d \theta_{F}+\int_{\widehat{\theta}_{F}}^{1}\left(-\widehat{t}_{F}\right) d \theta_{F} \equiv 0
$$

and compare this equation to the expected utility gain from attacking the foreign currency in (6). We know that $w\left(\theta_{F}\right)>1$ holds when a devaluation occurs in the foreign market (i.e., for $\theta_{F} \leq \widehat{\theta}_{F}$ ) and $w\left(\theta_{F}\right)<1$ holds when it does not. Since $\mu(w)$ is a strictly increasing function, the expression in (6) puts more weight on the positive term and less weight on the negative term, relative to (8), and hence must be strictly positive when evaluated at $\widehat{t}_{F}$. By continuity, therefore, the expected utility gain from attacking the foreign currency will be positive for an open interval of values of $t_{F}$ above $\widehat{t}_{F}$, even though the expected return from attacking in these cases is negative. This result clearly highlights the implications of the complementarity in wealth levels that naturally arises in the Morris-Shin model. An individual speculator's marginal utility of wealth is high in states where the wealth levels of other speculators are high. Therefore she would like to make the same risky trade(s) that the others are making, even if the trade would not be attractive on its own merits. This discussion is summarized in the following corollary. 
Corollary 1 Contagion can occur even when, in equilibrium, the expected return to attacking the foreign currency is negative.

This equilibrium with contagion has other appealing properties as well. For example, a larger devaluation of the foreign currency increases the probability of a domestic currency crisis. This result follows immediately from Proposition 1 and expression (5).

Corollary 2 In the contagion equilibrium, the probability of a domestic currency crisis is strictly increasing in the size of the devaluation of the foreign currency.

Also notice that the occurrence of a domestic currency crisis will be negatively correlated with domestic economic fundamentals. When $\theta$ is higher, a larger devaluation of the foreign currency is required in order to provoke a domestic devaluation. Hence crises will occur less frequently when domestic fundamentals are strong and more frequently when fundamentals are weak. This result and Corollary 2 both emphasize how the model presented here differs from the simple multipleequilibrium view of contagion. In the simple view, the outcome in the foreign market serves only as a signal to coordinate the beliefs and actions of speculators in the domestic market. This view offers no real explanation of which signals should lead speculators to attack the domestic currency or how likely these signals should be. In addition, it implies that, for all values of $\theta$ in multiple equilibrium region, the likelihood of a domestic currency crisis is independent of domestic fundamentals; a domestic crisis occurs if and only if the appropriate signal is received. ${ }^{10}$ The model here, in contrast, yields clear predictions that are consistent with the correlations observed in the data: a more severe currency crisis is more likely to prove contagious, and a crisis is more likely to occur when domestic economic fundamentals are weak.

\section{Discussion}

\subsection{Multiplicity of equilibrium}

Much of the interest in global-games analysis in macroeconomics comes from the fact that the models often have a unique equilibrium, which places comparative-statics analysis on solid footing

10 This fact is commonly used to criticize multiple-equilibrium models. See, however, Ennis (2003) and Ennis and Keister (2005a,b). 
and is potentially useful for conducting policy analysis. The results in Section 3.3 show how introducing a second market can lead to multiplicity of equilibrium, but they do not undermine the value of the global games approach. Quite to the contrary, the model presented here shows how using the global-games approach places a great deal of structure on equilibrium contagion.

Consider the "traditional" version of the model, where the state of the domestic economy is common knowledge. In this case, the domestic currency market (in isolation) has multiple equilibria for an interval of values for $\theta$. Once a second currency market is introduced, the outcome of this market can act as a signal that coordinates the actions of speculators in the domestic market, even they do not (or cannot) trade in this other currency. In particular, for each value of $\theta$ in the abovementioned interval, there can be a domestic crisis if the foreign currency devalues and not if it does not, or the reverse, or a crisis in both cases, or a crisis in neither case. Hence there is a large number of equilibria, including almost any possible correlation between outcomes in the two markets. The results presented above show how, in contrast, the global-games-based model determines the form that contagion must take if it occurs. The outcome of another currency market cannot act as a pure coordination device in this model. Contagion can only occur when speculators' beliefs lead them to be active in both markets. The nature of the markets then determines the form that equilibrium contagion must take: a sharp devaluation of the foreign currency increases the probability of a domestic currency crisis. In other words, the global-games approch ties equilibrium expectations to the economic environment in interesting and testable ways. The model predicts that existing financial links between markets are necessary for contagion to occur, and this prediction is broadly consistent with the results in the empirical literature.

Moreover, the model shows that empirical evidence on the sources of contagion should be interpreted with care. The fact that financial links predict the spread of crises does not imply that contagion is driven by underlying economic fundamentals nor that it is an inevitable outcome. Rather, these links could arise solely as a result of the expectation that contagion will occur and are therefore consistent with the existence of an equilibrium where financial links do not arise and no contagion occurs. Further research is needed to determine how important a role expectations have played in driving the observed spread of currency crises across countries. 


\subsection{A sunspots interpretation}

The results in this paper can be interpreted in a way that closely mirrors the classic paper of Cass and Shell (1983). Cass and Shell studied a standard Walrasian economy augmented to include "sunspots," a random variable that is completely extrinsic in the sense that it has no effect on economic fundamentals. They showed that when the underlying economy (without sunspots) has a unique equilibrium and agents cannot trade sunspot-contingent assets, sunspots cannot affect equilibrium allocations. This follows from the fact that in every sunspot state, the economy is exactly the same and hence the unique equilibrium must obtain. They then showed two ways in which sunspots can matter, one fairly obvious and the other much less so. First, suppose that the underlying economy has multiple equilibria. Then different equilibria might obtain in different sunspot states; that is, the realization of the sunspot variable might act as a signal that coordinates agents on a particular equilibrium. The sunspot equilibrium constructed this way is a randomization over the equilibria of the underlying economy. The second, and more interesting, case is when agents can trade assets whose payoffs depend on the realization of the sunspot variable. In this case, Cass and Shell showed that even when the underlying economy has a unique equilibrium, there can (under some conditions) be equilibria where sunspots affect allocations. If agents believe that the relative prices of commodities will depend on the sunspot state, they may want to use the asset market to transfer wealth across states. In some cases, this reallocation of wealth can cause the original expectations about prices to be fulfilled.

In the model presented in this paper, one can interpret the devaluation state of the foreign currency as a "sunspot-like" variable. Whether or not this currency devalues has no effect on the preferences of agents in the model nor on the fundamental state $\theta$ of the domestic economy. If speculators cannot trade in the foreign currency market, contagion can occur in equilibrium if and only if the domestic currency market (in isolation) has multiple equilibria. This is the "traditional" view of expectations-based contagion and is analogous to the first type of sunspot equilibrium described above, where the sunspot variable serves only as a signal that selects an equilibrium of the underlying economy. Discussion (and criticism) of expectations-based theories of contagion has focused on this particular form of contagion. The global-games approach, however, generates a unique equilibrium in the domestic currency market, and hence rules out this type of sunspot-like 
equilibrium. ${ }^{11}$ The model of contagion presented in this paper instead resembles the second, richer type of sunspot equilibrium. There is a unique equilibrium if trade on the foreign (or "sunspot") market is not allowed. Once such trade is introduced, however, beliefs that the equilibrium variables will differ across "sunspot” states can be self-fulfilling because agents will use this market to transfer wealth across states. Hence contagion driven solely by expectations can occur even when the currency market has a unique equilibrium, in precisely the same way that sunspot equilibria can exist even when the underlying Walrasian economy has a unique equilibrium. ${ }^{12}$

\subsection{Concluding remarks}

The analysis presented here has shown how contagion of currency crises can be driven solely by expectations, even in an environment where equilibrium is unique in each individual currency market. When speculators expect the occurrence of a crisis in the domestic market to be correlated with the outcome of some other market, they have an incentive to engage in trades that link the two markets together. These links can then propagate a crisis across the markets in a way that fulfills the original expectations. If speculators did not expect contagion to occur, these links may not be formed and contagion need not occur.

Many features of the model studied here are fairly special, but these do not seem essential for the results. For example, the assumption that speculators are risk neutral simplifies the analysis by generating boundary solutions to the spectators' portfolio-choice problem. Introducing risk aversion would complicate matters technically, but the effects highlighted here would clearly remain. Speculators would still have a higher marginal value of wealth in states where a devaluation of the domestic currency is more likely. If a speculator expects contagion to occur, therefore, she would still desire to transfer wealth into these states by short-selling the foreign currency. Other minor modifications of the model also seem unlikely to affect the main results.

The model (following Morris and Shin, 1998) does take a particular view of the nature of currency crises: they are caused by speculative attacks. Real world currency crises are complex phenomena and many of their features are obviously not captured by this model. For example,

\footnotetext{
11 See Heinemann and Illing (2002) on this point.

12 The analogy is not exact, of course. Cass and Shell (1983) require that some agents be restricted from trading before the sunspot state is realized; otherwise the first welfare theorem would guarantee that sunspots do not matter. In the present model, all agents can be granted access to the foreign market. In addition, Cass and Shell need heterogeneous agents for sunspot-contingent trade to occur in equilibrium. Here the homogeneous speculators are implicitly trading with the foreign central bank in the "sunspot" market.
} 
during times of crisis investors who hold real assets in a country tend to pull out, selling these local-currency denominated assets. Such movements put pressure on the local currency in much the same way that attacks by speculators do. Goldstein and Pauzner (2004) have shown, within a global-games framework, how a crisis caused by bad fundamentals in one country can be propagated to another country by investors who hold positions in both. While this mechanism of contagion is similar to the one studied here (contagion occurs due to financial links between markets) the underlying source of contagion in their model is fundamental; investors choose to take positions in multiple countries for diversification purposes. It would be interesting to investigate what role expectations can play in driving contagion when one takes their view (or others; see Guimaraes and Morris, 2004) of the basic nature of a currency crisis.

\section{REFERENCES}

Allen, Franklin and Douglas Gale (2000) Financial Contagion, Journal of Political Economy 108, pp. 1-33.

Cass, David and Karl Shell (1983) Do Sunspots Matter? Journal of Political Economy 91, pp. 193-227.

Dornbusch, Rudiger, Yung Chul Park, and Stijn Claessens (2000) Contagion: Understanding How It Spreads, World Bank Research Observer 15, pp. 177-197.

Eichengreen, Barry, Andrew K. Rose, and Charles Wyplosz (1996) Contagious Currency Crises, NBER Working Paper 5681, July.

Ennis, Huberto M. (2003) Economic Fundamentals and Bank Runs, Federal Reserve Bank of Richmond Economic Quarterly 89, 55-71.

Ennis, Huberto M. and Todd Keister (2005a) Government Policy and the Probability of Coordination Failures, European Economic Review 49, 939-973.

Ennis, Huberto M. and Todd Keister (2005b) Optimal Fiscal Policy with Multiple Equilibria, forthcoming in the Journal of Monetary Economics.

Gerlach, Stefan and Frank Smets (1995) Contagious Speculative Attacks, European Journal of Political Economy 11, pp. 45-63.

Glick, Reuven and Andrew K. Rose (1999) Contagion and Trade: Why are Currency Crises Regional? Journal of International Money and Finance 18, 603-617.

Goldstein, Itay and Ady Pauzner (2004) Contagion of Self-Fulfilling Financial Crises Due to Diversification of Investment Portfolios, Journal of Economic Theory 119, pp. 51-183. 
Guimaraes, Bernardo and Stephen Morris (2004) Risk and Wealth in a Model of Self-Fulfilling Currency Attacks, Cowles Foundation Discussion Paper No. 1433R, November.

Harsanyi, J. and R. Selten (1988) A General Theory of Equilibrium Selection in Games, MIT Press, Cambridge, MA.

Heinemann, Frank (2000) Unique Equilibrium in a Model of Self-Fulfilling Currency Attacks: Comment. American Economic Review 90, 316-318.

Heinemann, Frank and Gerhard Illing (2002) Speculative Attacks: Unique Equilibrium and Transparency, Journal of International Economics 58, 429-450.

Kaminsky, Graciela L. and Carmen M. Reinhart (2000) On Crises, Contagion, and Confusion, Journal of International Economics 51, 145-168.

Kodres, Laura E. and Matthew Pritsker (2002) A Rational Expectations Model of Financial Contagion, Journal of Finance 57, 769-799.

Krugman, Paul (1999) Balance Sheets, the Transfer Problem, and Financial Crises, International Tax and Public Finance 6, pp. 459-472.

Masson, Paul (1999) Contagion: macroeconomic models with multiple equilibria, Journal of International Money and Finance 18, 587-602.

Morris, Stephen and Hyun Song Shin (1998), Unique Equilibrium in a Model of Self-Fulfilling Currency Attacks, American Economic Review 88, 587-597.

Morris, Stephen and Hyun Song Shin (2003), Global Games: Theory and Applications, in Advances in Economics and Econometrics (Proceedings of the Eighth World Congress of the Econometric Society), edited by M. Dewatripont, L. Hansen and S. Turnovsky. Cambridge, England: Cambridge University Press.

Obstfeld, Maurice (1996) Models of Currency Crises with Self-fulfilling Features, European Economic Review 40, 1037-1047.

Pritsker, Matthew (2000) The Channels for Financial Contagion, mimeo., Board of Governors of the Federal Reserve System.

Van Rijckeghem, Caroline and Beatrice Weder (2001) Sources of Contagion: Is it Finance or Trade? Journal of International Economics 54, 293-308. 